\title{
Trimebutine maleate in the treatment of irritable bowel syndrome: Canadian clinical experience
}

ABSTRACT: An open multicentre study was conducted at 18 Canadian centres in patients diagnosed as suffering from irritable bowel syndrome (IBS). One hundred and thirty-one ( $72 \%$ female and $28 \%$ male) patients, mean age 44 years, were treated with $200 \mathrm{mg}$ tid trimebutine maleate (Modulon; Jouveinal) for periods of four weeks. Frequency and severity of pain, constipation and diarrhea were analyzed, as were stool frequency and consistency. A statistically significant reduction of frequency and severity was discerned in all symptoms (pain, constipation, diarrhea). Stool frequency fell within normal range (three per week to three per day) in close to $90 \%$ of patients as compared to $66 \%$ prior to the study. Similarly, stool consistency was normal in over $40 \%$ more patients at the end of the study than before treatment. Global evaluation by physicians and patients showed that approximately $70 \%$ of patients felt better at the end of the treatment than before the study. Side effects such as nausea, headaches and fatigue were reported in 14 patients, leading to discontinuation of therapy in seven. In conclusion, trimebutine maleate was effective in reducing the frequency and severity of the major symptoms of IBS as well as in normalizing transit disturbances as measured by stool frequency. Can J Gastroenterol 1987;1(1):23-27

Key Words: Constipation, Diarrhea, Irritable bowel syndrome, Pain, Trimebutine maleate

Participating centres: Dr J.G.D. Anderson, Dr J.D. Kempston, St Joseph's Health Centre, Toronto Ontario; Dr M. Beaudoin, Notre Dame Hospital, Montreal, Quebec; Dr M.R. Belsheim,

Dr R. Reynolds, St Joseph's Hospital, London, Ontario; Dr H.W. Bloom, North York Branson Hospital. Willowdale, Ontario; Dr D. Bondy, University Hospital, London, Ontario; Dr G. Choueri, Santa Cabrini Hospital, Montreal, Quebec; Dr D. Daly, Montreal General Hospital, Montreal. Quebec; Dr J. Gratton, Hotel Dieu Hospital, Montreal, Quebec; Dr G. Jobin, Dr G. Aumais, Dr R. Mousseau, Maisonneuve Rosemont Hospital, Montreal, Quebec; Dr R. Laurion, Hotel Dieu Hospital, St Jerome, Quebec; Dr M. Lichter, Jewish General Hospital, Montreal, Quebec; Dr W.W. Romatowski, St Catharine's General Hospital, St Catharine's, Ontario; Dr W. Whitfield, Greater Niagara General Hospital, Niagara Falls, Ontario; Dr N. Williams, Belleville General Hospital, Belleville, Ontario; Dr L.J. Worobetz, University Hospital, Saskatoon, Saskatchewan; Ms K. Farsky, Jouveinal Laboratories, Montreal, Quebec; MrR. Goyer, University of Montreal, Montreal, Quebec

Correspondence and reprints: Ms K. Farsky, Jouveinal Laboratories Inc, 1950-32nd Avenue, Lachine, Quebec H8T 3J7

Received for publication May 4, 1987. Accepted July 10, 1987
T HE GREAT MAJORITY OF PATIENTS with irritable bowel syndrome (IBS) present with a multitude of symptoms, all of which are often not responsive to a single agent such as anticholinergics or antispasmodics which are prescribed for pain, antidiarrheal agents, dietary fibre for transit disturbances and antidepressants/ anxiolytics for patients with associated psychological problems. Rather, a combination of several agents must often be prescribed. Thus, agents capable of controlling the entire symptom complex under monotherapy would offer an obvious advantage.

Trimebutine maleate (maleate salt of 2-dimethyl-amino-2-phenylbutyl 3,4,5 trimethoxy benzoate) was shown to stimulate motility in the small intestine and to modulate it in the colon, and to possess nonspecific spasmolytic activity associated with local anesthetic properties. Its stimulant activity appears to be related mostly to peripheral $\mu$ enkephalinergic agonist activity, while the inhibitory effect is mediated by its interaction with $\kappa$ receptors (1). In preclinical studies, it was shown to exert regularizing effect on abnormal contractility in vitro, as well as in vivo, where it induced phase III activity in dog intestine (2). In human intestine, it induces phase III activity (3), accelerates duodenal transit (4) and stim- 
ulates spike potential activity (5). These effects have been found useful in accelerating the resolution of postoperative paralytic ileus $(5,6)$. In the colon, the drug seems to exhibit bivalent action, as was demonstrated in studies where it reduced abnormally elevated and stimulated abnormally diminished colonic motor and electromyogenic activities (7-9). It appears to exert no effect on normal colonic activity $(3,7,8)$. Frexinos $(10)$ showed that the drug is active in both constipated and diarrheic patients in that it reduces colonic long spike burst electromyogenic activity. All these parameters seem to be related to the drug's ability to reduce clinical symptoms of IBS.

Numerous controlled clinical trials evaluating the effect of trimebutine maleate in the treatment of IBS have been completed (12-14). Short to medium term studies (three days to four weeks) comparing the drug to placebo showed that it is significantly more effective than placebo, particularly in relieving pain and constipation. Unpublished reports indicate that it also reduces diarrhea. Single stool transit time was significantly reduced in constipated patients with spastic colon (13). In a six month study. no significant differences in global assessment were found between the drug and placebo in patients treated concomitantly with high fibre diet, although colon tenderness was significantly reduced at three months (15). Studies comparing trimebutine to mebeverine $(16,17)$, anticholinergics such as pinaverium bromide (18) and clidinium bromide/chlordiazepoxide combination (19), showed equivalent efficacy in all treatment groups.

A post marketing open multicentre study was conducted in order to observe the effect of trimebutine maleate in the treatment of IBS and its various subgroups within the scope of routine gastroenterology practice.

\section{MATERIALS AND METHODS}

Eighteen Canadian centres participated in the study. Patient selection criteria included presence of chronic abdominal pain and/or transit disturbances such as constipation, diarrhea and alternation of the two. Patients must have had no evidence of organic gastrointestinal disease as demonstrated by barium enema, sigmoidoscopy, hemogram, blood biochemistry and/or lactose tolerance test. Only patients symptomatic at the time of entry into the study were to be included.

Patients were treated with two $100 \mathrm{mg}$ trimebutine maleate tablets three times a day ( 30 mins before meals) during four weeks, with follow-up every two weeks. Other medications for IBS were continued throughout the study with the exception of anticholinergics which were discontinued in all but two patients, starting at least $48 \mathrm{~h}$ prior to entry into the study. Although these two patients would have been excluded in a double-blind study analysis, they were included in this case.

During the trial, patients completed daily diary cards summarizing their intestinal habits and intensity of symptoms.

\section{TABLE 1}

Demographic data of patients with irritable bowel syndrome at 18 Canadian centres

\begin{tabular}{|c|c|}
\hline Total entered & 146 \\
\hline Total analyzed & $131^{\circ}$ \\
\hline Female & $72 \%$ \\
\hline Male & $27 \%$ \\
\hline Age (years) (mean \pm SEM) & $44 \pm 1.3$ \\
\hline $\begin{array}{l}\text { Duration of disease } \\
\text { (years) (mean } \pm \text { SEM) }\end{array}$ & $7 \pm 10.2$ \\
\hline \multicolumn{2}{|l|}{ Initial classification by symptoms } \\
\hline Pain & $89 \%$ \\
\hline Constipation & $33 \%$ \\
\hline Diarrhea & $25 \%$ \\
\hline $\begin{array}{l}\text { Alternating constipation/ } \\
\text { diarrhed }\end{array}$ & $33 \%$ \\
\hline \multicolumn{2}{|l|}{ Initial overall severity of IBS } \\
\hline Mild & $17 \%$ \\
\hline Moderate & $53 \%$ \\
\hline Severe & $22 \%$ \\
\hline Very severe & $2 \%$ \\
\hline \multicolumn{2}{|l|}{ Concomitant diseases } \\
\hline Cardiovascular & $8 \%$ \\
\hline Endocrine & $11 \%$ \\
\hline Immunological/allergic & $13 \%$ \\
\hline Gastrointestinal & $14 \%$ \\
\hline Other & $4 \%$ \\
\hline \multicolumn{2}{|l|}{ Concomitant IBS medications } \\
\hline Laxatives/bulk forming agents & $13 \%$ \\
\hline Anxiolytics & $14 \%$ \\
\hline Antispasmodics & $3 \%$ \\
\hline Antidiarrheals & $3 \%$ \\
\hline Antidepressants & $3 \%$ \\
\hline Analgesics & $6 \%$ \\
\hline Combination drugs & $2 \%$ \\
\hline Gl motility modifying agents & $1 \%$ \\
\hline
\end{tabular}

- 15 lost to follow-up

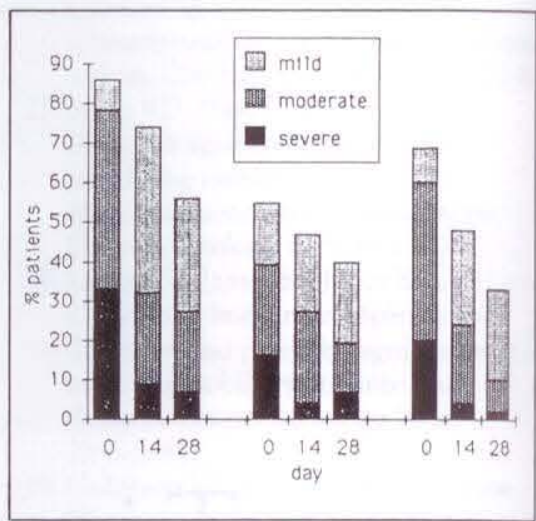

Figure 1) Severity of symptoms, all patients combined. Symptoms (from left to right) pain: constipation; diarrhea

At each visit, the investigators assessed the patients' clinical status, based on physical examination, review of daily diary cards and personal interviews. Severity of symptoms was assessed using a five point rating scale: 1 absent, 2 slight (present but not bothersome), 3 moderate (occasionally bothersome), 4 severe (bothersome most of the time), 5 very severe (incapacitating).

At the end of the four week period, both patients and investigators performed a global evaluation of the effect of the drug on the patients' condition. Change of symptom severity scores was evaluated for all patients and separately by symptom subgroups, as defined by investigators at time of patient enrollment (pain, constipation, diarrhea, alternation of constipation/diarrhea). Friedman's analysis over time was used to evaluate statistically changes relative to day 0 .

Study sample: Twenty-one investigators entered 146 patients at 18 centres throughout Canada. Fifteen patients failed to return after their initial consultation and were excluded from the study. Another 11 discontinued due to lack of improvement (four) or side effects (seven). The initial demographic data are summarized in Table 1. The usual spectrum of the syndrome was well represented in the study sample.

\section{RESULTS}

Symptom severity: A statistically significant reduction of severity was observed in all symptoms (pain, constipation, diarrhea) (Table 2, Figure 1).

At the start of the study, $91 \%$ of pa- 
TABLE 2

Symptom frequency and severity during treatment with trimebutine maleate (all patients combined)

\begin{tabular}{|c|c|c|c|c|}
\hline Symptom & Day 0 & Day 14 & Day 28 & $P \ddagger$ \\
\hline Pain & & & & \\
\hline Patients affected (\%) & 91 & 77 & 59 & $<0.005$ \\
\hline Mean severity score $( \pm$ SEM $) \dagger$ & $3.1 \pm 0.1$ & $2.2 \pm 0.1$ & $2.0 \pm 0.1$ & $<0.001$ \\
\hline Patients improved (\%) & & 63 & 72 & \\
\hline Number of days per week with pain & $4.9 \pm 0.2$ & $3.4 \pm 0.3$ & $2.6 \pm 0.3$ & $<0.001$ \\
\hline \multicolumn{5}{|l|}{ Constipation } \\
\hline Patients affected $(\%)^{*}$ & 56 & 47 & 39 & \\
\hline Mean severity score $( \pm$ SEM $) \dagger$ & $2.1 \pm 0.1$ & $1.8 \pm 0.1$ & $1.6 \pm 0.1$ & $<0.001$ \\
\hline Patients improved (\%) & & 37. & 39 & \\
\hline Number of stools per day ( \pm SEM) & $2.4 \pm 0.2$ & $1.6 \pm 0.1$ & $1.4 \pm 0.1$ & $<0.001$ \\
\hline \multicolumn{5}{|l|}{ Diarrhea } \\
\hline Patients affected $(\%)^{*}$ & 70 & 48 & 35 & \\
\hline Mean severity score $( \pm$ SEM $) \dagger$ & $2.5 \pm 0.1$ & $1.8 \pm 0.1$ & $1.5 \pm 0.1$ & $<0.001$ \\
\hline Patients improved (\%) & & 55 & 56 & \\
\hline Number of stools per day ( \pm SEM) & $4.4 \pm 0.3$ & $1.4 \pm 0.1$ & $1.2 \pm 0.1$ & $<0.001$ \\
\hline
\end{tabular}

- Missing data excluded; +1 Absent; 2 Slight; 3 Moderate; 4 Severe: 5 Incapacitating: $\ddagger$ Difference between day 0 and day 28

Symptom frequency and severity during treatment with trimebutine maleate (by initial tween day 0 and day 28 tients suffered from pain; at the end of four weeks treatment, it was present in $59 \%$ and the mean pain severity score diminished from 3.1 to 2.0. Similarly, while $56 \%$ of patients presented with constipation (with or without alternating diarrhea) at entry into the study, only $39 \%$ reported it at the end of the study and the mean severity score fell from 2.1

\section{TABLE 3} symptom subgroup classification)

\begin{tabular}{|c|c|c|c|c|c|}
\hline Subgroup & Symptom & Day 0 & Day 14 & Day 28 & Pf \\
\hline Pain & $\begin{array}{l}\text { Pain } \\
\text { Patients affected }(\%)^{*} \\
\text { Mean severity score }( \pm \text { SEM) } \dagger \\
\text { Patients improved }(\%) \\
\text { Number of days per week with pain }\end{array}$ & $\begin{array}{c}99 \\
3.3 \pm 0.1 \\
5.2 \pm 0.2\end{array}$ & $\begin{array}{c}83 \\
2.3 \pm 0.1 \\
69 \\
3.6 \pm 0.3\end{array}$ & $\begin{array}{c}62 \\
2.0 \pm 0.1 \\
78 \\
2.7 \pm 0.4\end{array}$ & $\begin{array}{l}<0.005 \\
<0.001 \\
<0.001\end{array}$ \\
\hline Constipation & $\begin{array}{l}\text { Constipation } \\
\text { Patients affected }(\%)^{*} \\
\text { Mean severity score }( \pm \text { SEM) }+ \\
\text { Patients improved }(\%)\end{array}$ & $\begin{array}{c}94 \\
3.4 \pm 0.2\end{array}$ & $\begin{array}{c}84 \\
2.5 \pm 0.2 \\
55\end{array}$ & $\begin{array}{c}66 \\
2.1 \pm 0.2 \\
65\end{array}$ & $<0.001$ \\
\hline Diarrhea & $\begin{array}{l}\text { Diarrhea } \\
\text { Patients affected }(\%)^{*} \\
\text { Mean severity score }( \pm \text { SEM) } † \\
\text { Patients improved }(\%)\end{array}$ & $\begin{array}{c}100 \\
3.2 \pm 0.1\end{array}$ & $\begin{array}{c}70 \\
2.1 \pm 0.2 \\
64\end{array}$ & $\begin{array}{c}59 \\
1.9 \pm 0.2 \\
74\end{array}$ & $<0.001$ \\
\hline Alternating bc & $\begin{array}{l}\text { wel habit } \\
\text { Constipation } \\
\text { Patients affected (\%)* } \\
\text { Mean severity score }( \pm \text { SEM)† } \\
\text { Patients improved }(\%)\end{array}$ & $\begin{array}{c}76 \\
2.3 \pm 0.2\end{array}$ & $\begin{array}{c}48 \\
1.8 \pm 0.2 \\
52\end{array}$ & $\begin{array}{c}42 \\
1.6 \pm 0.2 \\
80\end{array}$ & $<0.001$ \\
\hline & $\begin{array}{l}\text { Diarrhea } \\
\text { Patients affected }(\%)^{*} \\
\text { Mean severity score }( \pm \text { SEM)† } \\
\text { Patients improved }(\%)\end{array}$ & $\begin{array}{c}94 \\
3.0 \pm 0.1\end{array}$ & $\begin{array}{c}60 \\
1.7 \pm 0.1 \\
52\end{array}$ & $\begin{array}{c}35 \\
1.4 \pm 0.1 \\
84\end{array}$ & $<0.001$ \\
\hline
\end{tabular}

-Missing data excluded; $\uparrow 1$ Absent; 2 Slight: 3 Moderate; 4 Severe; 5 Incapacitating: $\neq$ Difference be-

to 1.6 . As for diarrhea, $70 \%$ of the patients had this symptom (with or without alternating constipation) at the start of the study and $35 \%$ at the conclusion. The mean diarrhea severity score was reduced from 2.5 to 1.5 .

These results were confirmed when the data were re-analyzed by symptom subgroups, (Table 3, Figure 2) based

Vol. 1 No. 1. October 1987 on classification presented at the onset of the study (pain, constipation and diarrhea).

In patients with alternating constipation and diarrhea, $58 \%$ and $65 \%$ no longer had constipation or diarrhea at the end of the study, respectively (as compared to $24 \%$ and $6 \%$, respectively prior to the study). The mean constipation severity score was reduced from 2.3 to 1.6 and diarrhea severity from 3.0 to 1.4 (Table 4).

Symptom improvement: After four weeks treatment, pain improved by at least one score level in $78 \%$ of patients in the pain subgroup, constipation in $65 \%$ and diarrhea in $74 \%$ of patients in the respective symptom subgroups. Over $80 \%$ of patients with alternating bowel habit showed improvement (Table 3). The mean severity score was reduced by 1.3 in all the subgroups.

\section{TABLE 4}

Stool frequency during treatment with trimebutine maleate

\begin{tabular}{lccc}
\hline & \multicolumn{3}{c}{ Number of stools per day } \\
Subgroup & Day 0 & Day 14 & Day 28* \\
\hline Constipation & $0.8 \pm 0.1$ & $1.1 \pm 0.2$ & $1.1 \pm 0.2$ \\
Diarrhea & $4.7 \pm 0.6$ & $2.7 \pm 0.3$ & $2.5 \pm 0.2$ \\
$\begin{array}{l}\text { Alternating } \\
\text { bowel habit }\end{array}$ & $4.4 \pm 0.3$ & $1.4 \pm 0.1$ & $1.2 \pm 0.1$ \\
\hline
\end{tabular}

- $P<0.001$ compared to day 0

Incidence of pain: In the pain subgroup, incidence of pain was significantly reduced from a mean of 5.2 to 2.7 days per week and the percentage of patients reporting pain decreased from 99 to $62 \%$ (Table 3).

Bowel habit: The number of patients with stool frequency within the normal range (three per day to three per week) increased significantly from 64 to $85 \%$ following treatment (Table 4, Figure 3).

Stool consistency became significantly $(\mathrm{P}<0.0001)$ more frequently normal in the entire study sample. Abnormal stool consistency (watery or hard) was reported $76 \%$ of the time prior to and $34 \%$ following treatment.

Global evaluation: Overall condition was assessed as better than before treatment in about $70 \%$ of the patients. Only six patients considered their condition worse (Table 5). 


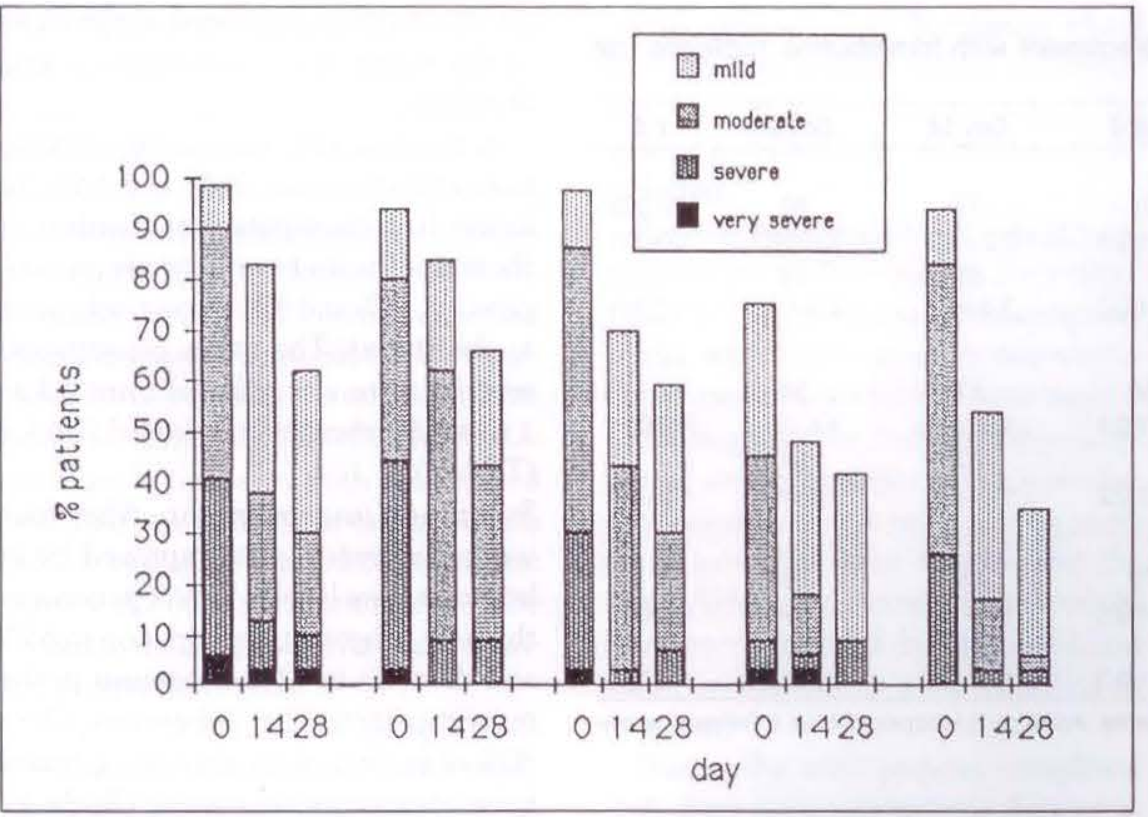

Figure 2) Severity of symptoms, separate symptom subgroups. Subgroups (from left to right) pain; constipation; diarrhea; constipation (with or without alternating diarrhea); diarrhea (with or without alternating constipation)

Side effects: Fourteen patients $(11 \%)$ reported side effects (Table 6). These lead to discontinuation of therapy in seven patients. Some of these reactions may have been related to the condition (eg, nausea) rather than to the drug.

\section{DISCUSSION}

Studies of effect of drugs on IBS typically pool all patient subgroups in their analysis. Separating the various symptom subgroups, as defined prior to therapy, refines the data analysis. This makes it possible to assess better the effect of a treatment on a particular symptom by including mostly symptomatic patients and excluding those suffering from symptoms that are at opposite extremes from

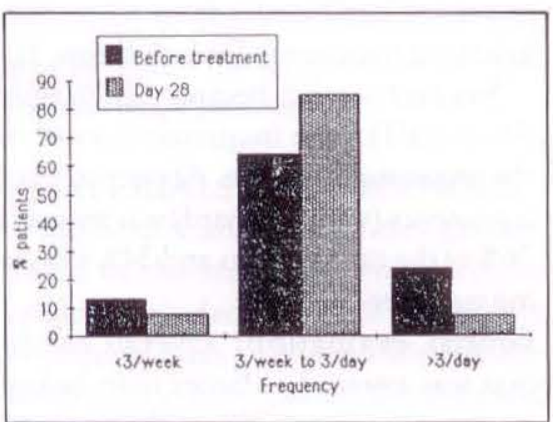

Figure 3) Stool frequency before and 28 days after treatment. Three per week to three per day is considered normal
TABLE 5

Global evaluation: Patient's overall condition at the end of treatment

\begin{tabular}{cccc}
\hline & Better & No change & Worse \\
\hline Physician's & 89 & 39 & 1 \\
assessment & $(69 \%)$ & $(30 \%)$ & $(1 \%)$ \\
Patient's & 84 & 29 & 6 \\
assessment & $(71 \%)$ & $(24 \%)$ & $(5 \%)$ \\
\hline
\end{tabular}

TABLE 6

Side effects of trimebutine

Side effect $\begin{gathered}\text { Number of } \\ \text { patients affected }\end{gathered}$

Nausea 4

Headache 3

Fatigue 1

Foul smell/taste $\quad 2$

Cutaneous rash/pruritus 1

Blurred vision 1 .

Dizziness + swelling of hands

Muscular pains 1

Total 14

- Concomitant glaucoma: + Not thought to be drug related

each other (eg, constipation/diarrhea).

Trimebutine maleate was shown to significantly reduce the frequency and severity of the major symptoms of IBS. Each of the symptoms improved in 65 to $80 \%$ of the patients reported to suffer from them. The trial confirmed results obtained in preclinical and clinical studies in that it exerts a bivalent action on gastrointestinal transit by normalizing stool frequency and consistency, regardless of the initial type of transit disturbance. This may be explained by trimebutine maleate's activity which may differ according to the different sites of the gastrointestinal tract (1) and/or the different activity states of the colon (3). Abdominal pain improved in over $80 \%$ of patients and disappeared in over $40 \%$.

Symptom improvement obtained with trimebutine maleate occurred within the first two weeks of treatment and was sustained or continued up to the end of the study. Patients continuing treatment beyond the duration of the study report continued long term benefit. It appears that, in certain patients, the efficacy of the drug increases with continued treatment. The drug was generally well tolerated and offers a viable all round therapeutic alternative in the treatment of IBS.

\section{REFERENCES}

1. Fioramonti J, Fargeas MJ, Bueno L. The involvement of opiate receptors in the effects of trimebutine on intestinal motility in the conscious dog. J Pharm Pharmacol 1984:36:618-21.

2. Poitras P, Havrankova J, Trudel L, Junien JL, Goyer R, Pascaud X. Effect of trimebutine, an opiate-like agonist on motility of the small intestine and the plasma levels of motilin, gastrin and insulin in the dog. Gastroenterology 1985:88:1541. (abst)

3. Valori RM, Shannon S, Reddy SN, Campbell D, Collins SM. The action of trimebutine on gastrointestinal motility in humans is mediated by opiate receptors. Gastroenterology 1985; 88:1622.

4. Schang JC, Muller J, Rico E, Grenier JF. Effets accélérateurs de Débridat (trimebutine) sur le transit duodénal. Med Chir Dig 1982;11:371-4.

5. Grenier JF, Schang JC, Dauchel J.Etude électromyographique des effets de la trimébutine sur la motricité intestinale au cours de la période post-opératoire J Med Strasbourg 1977; 8:335-8.

6. Cinqualbre J. Lampert M, Avalos S, Forster E. Essai clinique d'un nouveau péristaltrogène agissant au niveau des synapses digestives. J Med Strasbourg 1973:4:973-6.

7. Meunier P. Effets de la trimébutine sur la motricité colique dans les colopathies. Gastroenterol Clin Biol 1980;4(1 bis):261A.

8. Isman H, Lupo B, Narache R. Effet Débridat (trimébutine) sur la motricité 
sigmoïdienne et recto-sigmoidienne chez le sujet normal et chez le colopathe. Gaz Med Fr 1982;89:1272-6.

9. Reboa G, Bertoglio C, Terrizzi A, et al. L'azione della trimebutina sull'attivita elettrica e manometrica del colon normale e patologico. Riv Gastro-Enterol $1976 ; 28: 1-16$

10. Frexinos J, Fioramonti J, Bueno L. Effect of trimebutine on colonic myoelectrical activity in IBS patients. Eur J Pharmacol 1985;28:181-5

11. Devroede G. The irritable bowel syndrome: clinical and therapeutical aspects. In: Poitras P, ed. Small Intestinal and Colonic Motility. Proceedings of the first international symposium. Montreal: Jouveinal Laboratories, 1984:129-39.

12. Lüttecke K. A trial of trimebutine in spastic colon. J Int Med Res 1978;6:86-8.

13. Moshal MG. A clinical trial of trimebutine (Mebutine) in spastic colon. J Int Med Res 1979;7:231-4.

14. Lee SW. Essais cliniques de la polybutine (trimebutine maleate) sur les "irritations coliques" (irritable colon) New Med ] 1981;24(9): 1-6.

15. Fielding JF. Double blind trial of trimebutine in the irritable bowel syndrome. Ir Med J 1980;73:377-9.

16. Lüttecke K. A three-part controlled study of trimebutine in the treatment of irritable colon syndrome. Curr Med Res Opin 1980:6:437-43.

17. Toussaint J. Etude en simple aveugle de la trimébutine et de la mebeverine dans le colon irritable et la dyspepsie. Acta Therap 1981;7:261-8.

18. Corazza GR, Varira D. Milletti S, Vanziri S, Gasbarrini G. Controlled clinical evaluation of pinaverium bromide and trimebutine in functional disorders of the colon. Acta Therap 1983;9:383-9

19. Copé R. Etude clinique comparative de l'association clidinium (br) - chlordiazepoxide et de la trimébutine dans le traitement des colopathies fonctionnelles. MCD 1981:10(8)-713-7. 


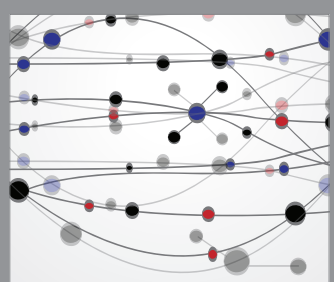

The Scientific World Journal
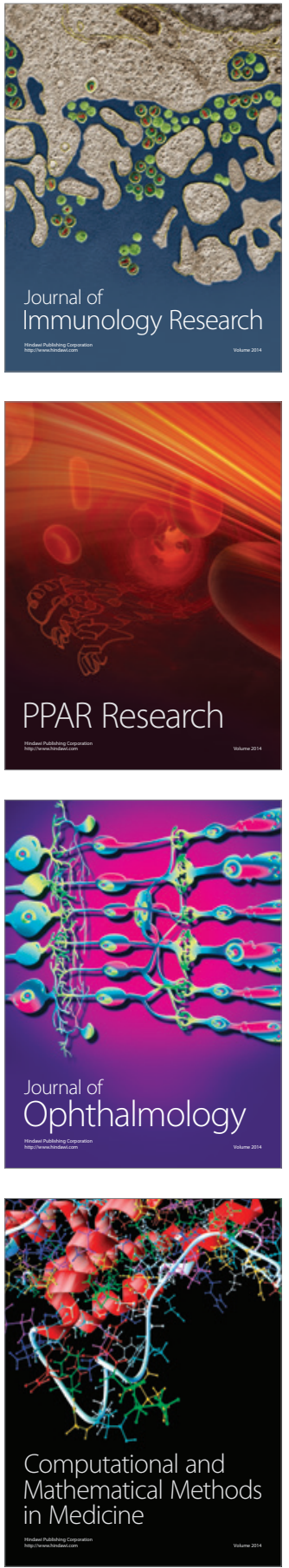

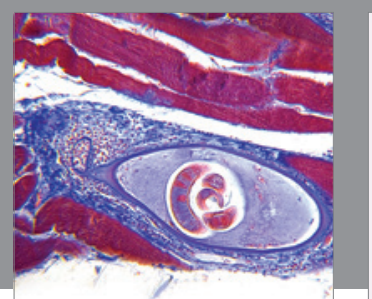

Gastroenterology Research and Practice

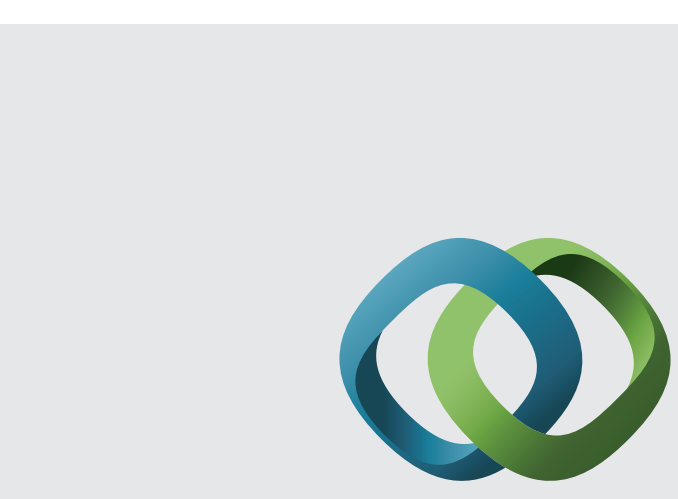

\section{Hindawi}

Submit your manuscripts at

http://www.hindawi.com
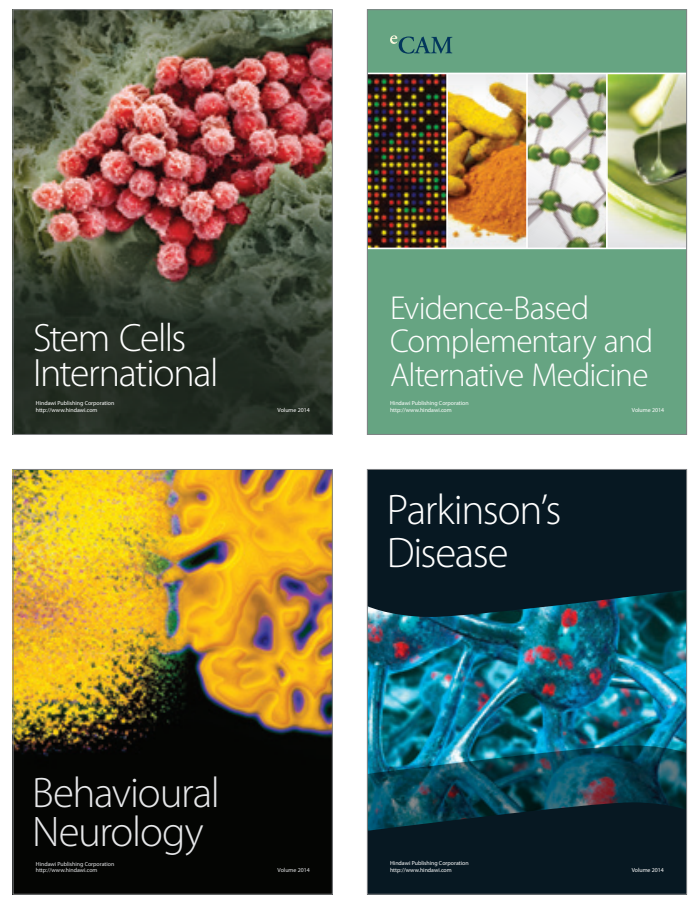
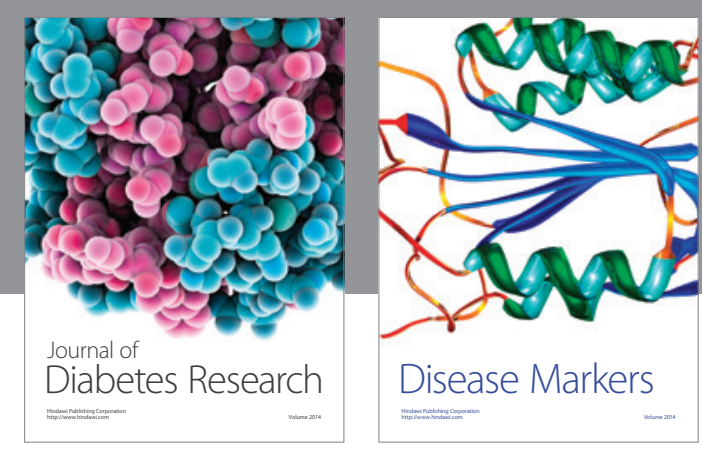

Disease Markers
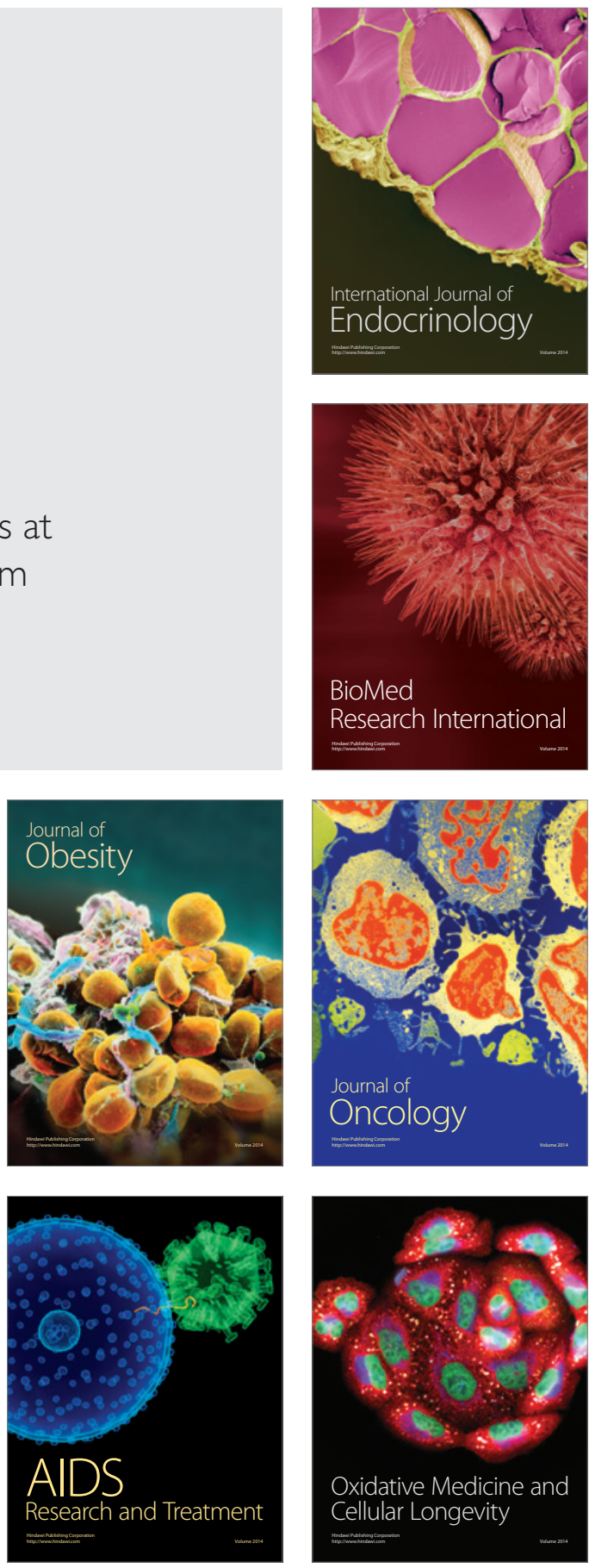